\title{
Editorial
}

\section{The discourse of 'biocultural' rights and the search for new epistemic parameters: moving beyond essentialisms and old certainties in an age of Anthropocene complexity?}

There can be little doubt of the multiple complexities facing law in the twenty-first century. Climate change alone presents a challenge of unprecedented global complexity for legal systems - a complexity arising, moreover, directly from the 'complexity of the climate system [itself:] its myriad of parts, interactions, feedbacks and unsolved mysteries'. ${ }^{1}$ In the face of such complexities, law's traditional institutional silos and path-dependent responses (such as the institutional and doctrinal separation between, for example, human rights law and climate change law) seem increasingly exposed as inadequate.

Law's path-dependent institutional and doctrinal structures relate to deeper conceptual tendencies. While law itself is a complex, multi-layered phenomenon, it famously trades in binaries, taxonomies and other conceptual reductionisms. This - it is increasingly clear - is a deep-seated orientation ill suited to the complexity of rapidly mutating, polycontextural, densely interwoven contemporary predicaments.

The urgency of climate change - and the deep challenge it presents - in particular to the settled categories of traditional juridical subject-object relations - in part explains the growing contemporary interest among legal scholars in new materialist and posthumanist onto-epistemologies. ${ }^{2}$

Such approaches - with their insistence on the deconstruction of traditional subjectobject relations - emphasize the ultimate impossibility of separating the "natural' and the 'cultural'. And while this is not because of the Anthropocene discourse that locates 'humanity' as the geological force behind the climate crisis, the challenge presented by new materialist ontologies is certainly an enriching philosophical one to bear in mind when thinking about biocultural rights discourse - as is the emergent construct of the Anthropocene species-subject.

Among other things, at the heart of Anthropocene discourse is an important tension that also emerges in biocultural rights discourse. This is the tension between a universalized conception of 'humanity' (or of any of its sub-groups) and the related risks of freighting all such 'identities' (universal and localized) with essentialisms. Essentialisms,

1. J Rial et al., 'Nonlinearities, Feedbacks and Critical Thresholds within the Earth's Climate System' (2004) 65 Climate Change 11-38 at 33.

2. A turn towards the work of Karen Barad, Donna Haraway, Manuel De Landa, Jane Bennett and others. What such accounts have in common is a sense of the lively agency of matter itself and the refusal of traditional subject-object relations that place a human epistemic agent at the 'centre' of the 'world'. For a brief and inspiring application of a broadly new materialist ontoepistemology to human rights, drawing directly on the work of Barad, see A Neimanis, 'Alongside the Right to Water, a Posthumanist Feminist Imaginary' (2014) 1 Journal of Human Rights and the Environment 5-24. 
in short, stalk Anthropocene 'humanity' and the human subjects of biocultural rights alike - throwing an unsettling shadow that presents important critical questions concerning both discourses as they attempt to address environmental crisis.

Anthropocene discourse - as is well understood - insists that the planet has entered an epoch in which 'humanity' has emerged as a geological force (anthropos ('human being/ man') and kainos ('new'/current')), ${ }^{3}$ as a result of the 'large-scale human modification of the Earth System, primarily in the form of climate change, the most salient and perilous transgression of Holocene parameters' ${ }^{4}$ For Chakrabarty, the Anthropocene trope suggests that 'humanity' stands freshly united in a new negative human universality predicated upon common vulnerability in the face of climate crisis. ${ }^{5}$ Certainly, the arrival of the Anthropocene problematizes traditional subject-object relations. It also complicates the traditional separation between natural and cultural histories - as Chakrabarty argues. ${ }^{6}$ The overarching Anthropocene sense of a new, universal humanity bearing responsibilities towards the planet also carries the promise of a more eco-responsive normativity - a normativity reflected in biocultural rights discourse - but it remains critical to counterbalance this 'new' Anthropocene 'human commonality' with the fact that human universals remain stubbornly marked by histories, presents and future histories of profound hierarchical inequality.

Climate vulnerability - notwithstanding its universal salience - remains differentially distributed, and the patterns of climate injustice point unerringly to the profound precarity of the historically most exploited human sub-groups. In short, if there is a new Anthropocenic 'humanity', it is marked by savagely predictable hierarchies in which the very communities currently envisaged at the heart of biocultural rights discourse ('indigenous peoples and local communities') stand systemically disadvantaged by the international legal order itself.

Biocultural rights discourse emerges, then, into a situation marked by contemporary climate complexity, the emergence of the Anthropocene human subject, new materialist understandings of 'nature-culture' and an intensifying search for adequately calibrated forms of climate justice - all this against the background of violent, globally salient, hierarchies imposed upon human beings, non-human animals and ecosystems throughout long, distinctively patterned histories of privilege and predation - of which the climate crisis itself should be seen as a powerful symptom.

As will become apparent in this edition of the Journal of Human Rights and the Environment (JHRE), biocultural rights discourse - seen against such challenges promises new, epistemically-sensitive responses to environmental crises both local and international by drawing upon a juridical epistemology sensitive to embodied location. However, this edition also suggests that biocultural rights discourse does not yet offer a fully developed critical politics of location richly sensitive to the risks of essentialism. The edition brings two invigorating contributions on biocultural rights discourse into direct proximity with each other. The first contribution traces the emergence and justificatory foundations of biocultural rights; the second, while welcoming biocultural rights, suggests tensions conceptually implicit in their nascent structure. The edition then turns to three more general contributions, which can, in different ways, each be related to the centrally important and intimately related question of epistemic parameters.

3. PJ Crutzen, 'Geology of Mankind' (2002) 23 Nature 415.

4. A Malm and A Horborg, 'The Geology of Mankind? A Critique of the Anthropocene Narrative' (2014) 1/1 The Anthropocene Review 62-69 at 63.

5. D Chakrabarty, 'The Climate of History: Four Theses' (2009) 35 Critical Inquiry 35:197-222.

6. Ibid. 
The edition begins, appropriately enough, with Kabir Bavikatte and Tom Bennett's article: 'Community stewardship: the foundation of biocultural rights'. Bavikatte is credited with first identifying the emergence of biocultural rights in international environmental law by drawing upon a combination of multilateral environmental agreements, domestic laws and shifts in development discourse and patterns of community struggle in order to trace an emergent 'basket' of 'biocultural rights'.

For Bavikatte and Bennett (this edition), the term 'biocultural rights' 'denotes a community's long established right, in accordance with its customary laws, to steward its lands, waters and resources'. Biocultural rights is thus a nascent category, at the heart of which lies the collective nature of the rights, their content turning on the rights of 'communities' to 'carry out traditional stewardship roles vis-à-vis Nature, as conceived of by indigenous ontologies'. Such rights minimally carve out, then, normative space for indigenous communities to express their traditional cosmological and socio-ecological relationships with place - relationships temporally extended into the deep past and drawing upon traditional indigenous ontologies and epistemic practices.

Bavikatte and Bennett go further than this, however, by explicitly conceptualizing biocultural rights as the expression of one side of a binary pair of potential 'solutions' to ecological crises. The authors place mainstream 'technocratic solutions' against solutions 'derived from the experiences of local communities that have long-term attachments to the soil' to offer a located strategy - staying close to established patterns of relationship with particular places - but pointing beyond such locations to the wider sense of human commonality in the face of environmental crisis (also evoked by Anthropocene discourse). The avowed aim of Bavikatte and Bennett's argument is to "elaborate and make a case for "biocultural rights" as a means to secure ... community led solutions', and the very term biocultural, suggest Bavikatte and Bennett, indicates a holistic relationship between nature and culture, affirming 'the bond between indigenous, tribal and other communities with their land, together with the floral, faunal and other resources in and on the land' - in short, a 'stewardship' relationship.

Their use of the language of 'resources' suggests that Bavikatte and Bennett do not go so far as to embrace a conception of nature-culture. Their framing continues to resonate with an anthropocentric implication that may, in turn, simply reflect the origins of biocultural rights in international environmental agreements. Bavikatte and Bennett do insist, however, on a profound intimacy between nature and culture - and the authors position indigenous peoples and local communities as the special repositories of such intimate relationalities - with important implications for duties of environmental stewardship. There are, however, as Sajeva argues in this edition, certain perils lurking in such a formulation.

For Giulia Sajeva, in 'Rights with limits: biocultural rights - between selfdetermination and conservation of the environment', Bavikatte's conception of biocultural rights is a welcome and promising development. It has, however, certain ambivalent implications. Sajeva argues that biocultural rights suppose two conceptual foundations: on the one hand the self-determination and the cultural diversity of indigenous peoples and local communities - and on the other, the "conservation of the environment'. For Sajeva, while the second of these foundations opens human rights discourse usefully to environmental considerations and presents a certain sui generis potential, it is important to remain wary of implicit essentialisms in Bavikatte's formulation, and of the related danger of inequitable levels of environmental responsibility being placed upon the holders of biocultural rights.

Biocultural rights, as Bavikatte and Bennett's argument makes explicit, protect the interests of indigenous peoples and local communities, in particular by respecting 
traditional indigenous and local duties of environmental stewardship. However, Sajeva argues that this formulation is potentially burdensome - not least because the second foundation imports a general duty burdened by humankind-in-general's interest in the conservation of the environment. For Sajeva, accordingly, the holders of biocultural rights 'take on a potentially inequitable duty towards environmental sustainability that limits their self-determination interests'.

Sajeva's critique implies the further possibility (not adverted to in her article) that biocultural rights also construct indigenous peoples and certain local communities as special bearers of a problematic degree of Anthropocene responsibility, drawing upon an essentialization of indigeneity itself. Bavikatte's formulation, in other words, may signal considerations inviting a more careful critical treatment than they have yet received in this energetic and important new rights discourse. Such tensions suggest the need for continuing critical attentiveness to the subjects constructed by the discourse - particularly when read against neo/colonial reproductions of essentialized indigenous subjects and when placed against the broader potential for Anthropocene discourse to occlude important patterns of climate injustice in its production both of Anthropocene 'humanity' and of 'environmental responsibility'.

Bavikatte and Bennett's contribution establishes - importantly - the need to diversify epistemic inputs into the formulation of legal responsibilities, inviting historically marginalized communities and indigenous epistemic agency into the frame of analysis. Sajeva is right, however, to raise the questions that she does - and right too, it is suggested, to welcome and support the emergence of biocultural rights precisely by pointing to future research questions implicated by the trajectory of the discourse.

A particular strength of biocultural rights discourse is its invitation to see the need for a renewing epistemic inquiry concerning plural normativities and to address the interface between diverse communities and a state-led system of international environmental law and human rights. If the Anthropocene context makes anything clear, it is the destructive effect of the 'epistemology of mastery' - the dominant epistemology lying behind the technocratic solutions that Bavikatte and Bennett so emphatically eschew in favour of turning to diverse ecologies of indigenous insight.

The fundamental insistence on the need for a more diverse set of epistemic inputs, and for richer, plural ontological narratives, raises an important - and more general - question concerning how law, and environmental law in particular, can open itself to a more diverse, epistemological imaginary. This search lies at the heart of Tiina Paloniitty's contribution to this edition.

Paloniitty also turns, in a sense, to situated complexity - but rather than drawing from indigenous ontologies and epistemic practices and eco-traditions, Paloniitty turns to the complexities and challenges presented to 'modern environmental law' by ecological science. Paloniitty locates her enquiry within civil law systems to examine the misalignment between traditional conceptions of judicial decision making and the more complex realities presented by the impossibility of separating (in any ultimate or stable way) 'normative' and 'factual' premises. This challenge - again resonant with implications explored by new materialist philosophy - requires, Paloniitty argues, a new way of formulating judicial decisions. Paloniitty responds to this challenge by presenting what she calls 'legal ecology' - one response, she suggests, to 'the search for more mature environmental methodologies'.

Legal ecology, Paloniitty suggests, is drawn from the writings of Ronald Dworkin and Robert Alexy, adapting the 'concept of principles as optimization requirements' to operationalize and fulfil what Paloniitty refers to as the 'aim-setting' sections of environmental regulation. The aim-setting sections, on this approach, are framed as ways of clarifying 
broader environmental legal principles, which are 'filtered and sorted' in the aim-setting sections. The operation of the aim-setting sections as principled optimization requirements means that they are more responsive, Paloniitty's argument implies, to normative and factual possibilities (keeping in mind what she argues about the ultimately porous boundary between normative and factual premises). Paloniitty suggests the need to formalize the weighing of competing legislative values and objectives - arguing that the formalization of such balancing should become the judicial norm. Her hope is that this kind of interpretive, adjudicative methodology will allow judicial decision making better to respond to the complexity of the issues involved in the deterioration of ecosystems and bring about a "paradigmatic shift ... in the kind of judicial decision-making which is carried out on a daily basis'.

Paloniitty's contribution reflects a growing awareness of environmental pressures and their implications for the way that human normative relations and juridical arrangements are to be conceptualized and operationalized - an awareness also reflected by the emergence of biocultural rights discourse. The fourth article in this edition addresses this broad theme by turning to examine a theoretical gap in contemporary accounts of the growing trend towards the constitutional enactment of environmental rights implicitly underlining, yet again, the question of epistemic parameters and how they mediate human-environmental dynamics.

In 'Explaining the emergence of constitutional environmental rights: a global quantitative analysis', Josh Gellers argues that there has been a general failure to explain the international phenomenon of the constitutionalization of environmental rights in 'a systematic fashion'; and, specifically, that no account has yet been provided from an international relations perspective. Gellers proposes to address the gap by offering a systematic analysis of this 'global development in constitutional design'.

Significantly, Gellers' analysis reveals the potency of civil society influences, the legacy of human rights and the vibrancy of democratic structures and values as key drivers of the expansion of constitutional environmental rights discourse. What emerges from his analysis is a picture in which a combination of internationally salient normative drivers and domestic political conditions provide 'greater analytical leverage than materialist considerations such as money or power'. While Gellers' definition of power may invite questions concerning its precise meaning and implications, it is clear that his careful social science research methods account reveals the pivotal importance of living political and normative energies in the emergence of constitutional environmental rights, offering an empirically nuanced and systematic account of this salutary and timely shift in the international normative arena.

Gellers suggests that further research 'would [itself] benefit by improving the coverage and quality of data used to operationalize relevant theoretical perspectives and testing new variables, such as the adoption of international treaties, the presence of environmental NGOs, or judicial independence, which may offer additional explanatory value'. He concludes that constitutional environmental rights represent 'an important development at the nexus of government, human rights and nature, whose impacts are thus far poorly understood', and that future empirical work will provide the only real way to determine whether such legal innovations offer anything more than 'mere window dressing'. Gellers, rather like Bavikatte and Bennett, Sajeva and Paloniitty, draws us towards the actual - towards open epistemic engagements with situated issues and questions in the midst of immense complexity.

This theme of situated epistemic sensitivity and its potential for addressing the complexity of challenges faced by environmental law is also reflected in the final 
contribution to this edition. Paul Anderson, in 'Which direction for international environmental law?' (IEL) addresses the intense challenge facing IEL of facilitating 'the resolution of environmental problems faster than they are being caused'. Anderson's analysis of this central question necessitates an evaluative analysis of candidate foundations for substantive IEL. Anderson compares two particularly prominent candidate foundations: neoclassical economic theory (NET) and 'distributive justice and deliberative democratic theories'. Anderson argues that notwithstanding NET's undoubted influence, its expansion of strategies for the privatization and pricing of nature is counterproductive. Rather, the solution lies in the direction of 'subsuming markets within an expanded and enriched public sphere 'characterized, inter alia, by decentralized, deliberative democratic decision-making'. However, Anderson's is not a simple restatement of traditional deliberative democratic theories: for him, the challenges of sustainability mean that it is essential to combine such essentially process-based responses with 'common key resource control' - in short, to blend deliberative process with 'economic democracy'. This offers, he suggests, a plausible foundation for IEL by ensuring a viable degree of sensitivity to the complexity of the problems it faces, and simultaneously offers 'guidance for incipient efforts to democratize environmental regulation'.

Anderson's argument invites precisely the kinds of situated sensitivities and the breadth of participatory engagement that could ensure a greater degree of inherent sensitivity to the complexity of environmental problems - and which chimes well with the other contributions to this edition. In this sense, Anderson's contribution returns us to the central emphasis of biocultural rights discourse upon the need to develop situated, culturally sensitive, inclusive and meaningful modes of epistemic responsiveness in law and governance paradigms.

It is difficult to avoid the implication of the contributions to this edition, taken together, that the complexity of the challenges facing law in the twenty-first century will continue to demand powerful new forms of epistemic inclusivity and critical vigilance. Whether the subject of reflection is biocultural rights, judicial methodologies, shifting international normative trends, contemporary research methods and their frameworks or the question of alternative foundations for international environmental law - there is a deepening sense, reflected by this edition of the JHRE, in which nothing short of a renewed commitment to radical epistemic humility and a determination to learn from patterns of injustice will enable the writing of future histories reaching beyond the misleading certainties, traditional subject-object relations and epistemic closures which have, for too long, underpinned the realm of the juridical.

Anna Grear Editor in Chief 